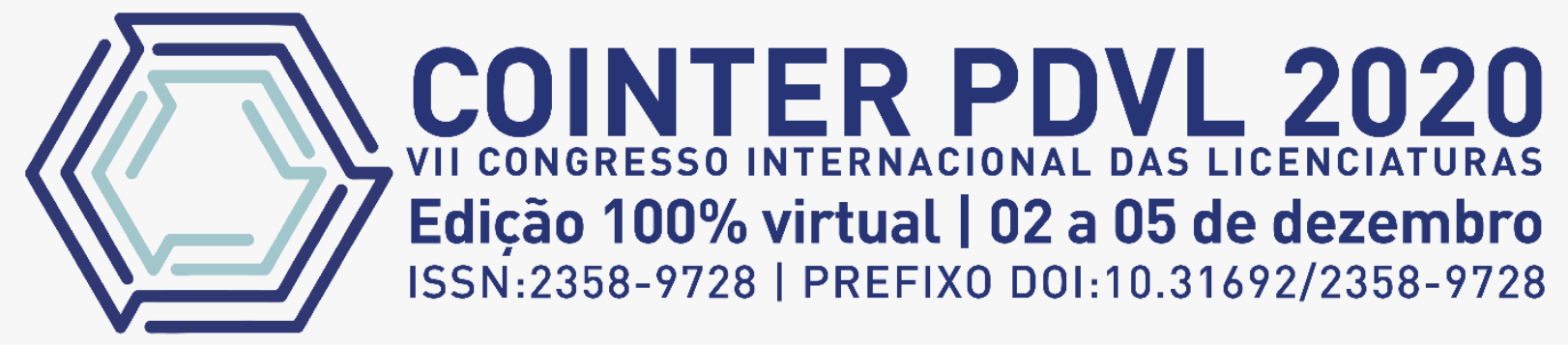

\title{
POPULARIZAÇÃO DA CIÊNCIA, SENSO COMUM E O PAPEL DO PROFESSOR NO ENSINO DE CIÊNCIAS
}

\author{
POPULARIZACIÓN DE LA CIENCIA, SENTIDO COMÚN Y EL PAPEL DEL \\ PROFESOR EN LA ENSEÑANZA DE LAS CIENCIAS
}

\section{SCIENCE POPULARIZATION, COMMON SENSE AND THE TEACHER'S ROLE IN SCIENCE TEACHING}

\author{
Apresentação: Comunicação Oral \\ João Pedro Gomes Alves Ferreira ${ }^{1}$; Marcelo Gomes Germano ${ }^{2}$
}

DOI : https://doi.org/10.31692/2358-9728.VIICOINTERPDVL.0358

\begin{abstract}
RESUMO
Este trabalho apresenta uma discussão sobre a aproximação entre o conhecimento elaborado cientificamente e os saberes do senso comum na perspectiva daqueles esforços comumente denominados de Popularização da Ciência. Para tanto, defende-se a consideração da leitura e visão do mundo dos sujeitos integrantes dos processos educativos, aliada a uma apresentação diferenciada do conhecimento científico, isto é, a apresentação da ciência como produto, mas sobretudo, como um processo que pode se adequar as realidades local e regional do educando. Dessa forma se dará o estabelecimento de um diálogo que seja capaz de desvelar as singularidades do real. Objetivando atingir as características de um ensino de ciências dialógico-democrático, cabe ao professor como responsável pela apresentação da atividade científica, assumir a postura do educador-educando que se coloca como um constante aprendiz ao procurar continuamente apreender os saberes de experiências feitos dos educandos e iniciar um processo de colaboração, entre ele, o intelectual compromissado com seu conhecimento científico, e o povo com as suas percepções primeiras sobre a realidade. Dessa forma, apresenta-se as justificativas para a promoção da Popularização da Ciência nos espaços educativos, refletindo os desafios e as limitações impostas pela realidade a cada uma delas. Nesse sentido, a pedagogia da pergunta é considerada como princípio pedagógico norteador da prática educativa, contrapondo-se a hegemônica educação de respostas, exímia especialista em depositar conhecimentos. Criadas e estabelecidas as condições para o diálogo entre o conhecimento científico e os saberes de senso comum, inaugura-se a possibilidade de um ensino de ciências capaz de auxiliar os sujeitos das classes populares a atuarem na sociedade a partir de conhecimentos científicos básicos, permitindo-lhes, homens e mulheres, a seguirem a sua ontológica vocação: de ser mais.
\end{abstract}

Palavras-Chave: Ciência, Senso Comum, Popularização.

\section{RESUMEN}

Este trabajo presenta una discusión sobre la aproximación entre el conocimiento elaborado

\footnotetext{
${ }^{1}$ Mestrando em Ensino de Ciências e Educação Matemática, Universidade Estadual da Paraíba (UEPB), jpferreira117@gmail.com

${ }^{2}$ Doutor, Universidade Estadual da Paraíba (UEPB), mggeramo24@gmail.com
} 


\section{POPULARIZAÇÃO DA CIÊNCIA, SENSO COMUM E O PAPEL DO PROFESSOR}

científicamente y el conocimiento de sentido común en la perspectiva de esos esfuerzos comúnmente denominados Popularización de la Ciencia. Para ello, se propugna la consideración de la lectura y cosmovisión de los sujetos que forman parte de los procesos educativos, combinada con una presentación diferenciada del conocimiento científico, es decir, la presentación de la ciencia como un producto, pero sobre todo, como un proceso que se puede adaptar. las realidades locales y regionales del alumno. De esta forma, se establecerá un diálogo que sea capaz de revelar las singularidades de lo real. Con el objetivo de alcanzar las características de una enseñanza de la ciencia dialógico-democrática, le corresponde al docente como responsable de la presentación de la actividad científica, asumir la posición del educador-alumno que se coloca como un aprendiz constante al buscar continuamente aprehender el conocimiento de las experiencias realizadas por los estudiantes y iniciar un proceso colaborativo, entre él, el intelectual comprometido con su conocimiento científico, y las personas con sus primeras percepciones sobre la realidad. Así, se presentan las justificaciones para impulsar la Popularización de la Ciencia en los espacios educativos, reflejando los desafíos y limitaciones que la realidad impone a cada uno de ellos. En este sentido, la pedagogía de la pregunta es considerada como el principio pedagógico rector de la práctica educativa, en contraposición a la respuesta hegemónica de la educación, experta en depositar conocimientos. Creado y establecido las condiciones para el diálogo entre el conocimiento científico y el conocimiento de sentido común, la posibilidad de una educación científica capaz de ayudar a los sujetos de las clases populares a actuar en la sociedad desde los conocimientos científicos básicos, abre la posibilidad ellos, hombres y mujeres, para seguir su vocación ontológica: ser más.

Palabras clave: ciencia, sentido común, popularización.

\section{ABSTRACT}

This paper presents a discussion about the approximation between scientifically elaborated knowledge and common sense knowledge in the perspective of those efforts commonly called Science Popularization. To this end, it is advocated the consideration of the reading and world view of the subjects that are part of the educational processes, combined with a differentiated presentation of scientific knowledge, that is, the presentation of science as a product, but above all, as a process that can be adapted the local and regional realities of the student. In this way, a dialogue will be established that is capable of revealing the singularities of the real. Aiming to achieve the characteristics of a dialogicaldemocratic science teaching, it is up to the teacher as responsible for the presentation of the scientific activity, to assume the position of the educator-student who places himself as a constant apprentice when continuously seeking to apprehend the knowledge of experiences made by the students and initiate a collaborative process, between him, the intellectual committed to his scientific knowledge, and the people with their first perceptions about reality. Thus, the justifications for promoting the Popularization of Science in educational spaces are presented, reflecting the challenges and limitations imposed by reality to each one of them. In this sense, the pedagogy of the question is considered as the guiding pedagogical principle of educational practice, in contrast to the hegemonic response education, an expert in depositing knowledge. Created and established the conditions for the dialogue between scientific knowledge and common sense knowledge, the possibility of a science education capable of helping the subjects of the popular classes to act in society from basic scientific knowledge, opens up the possibility them, men and women, to follow their ontological vocation: to be more.

Keywords: Science, Common Sense, Popularization.

\section{Introdução}

A nação que deseja prosperar nas dimensões da tecnologia para otimização dos processos de produção de bens, energia e desenvolvimento de produtos, não pode dispensar os benefícios da ciência. O mesmo se aplica ao desenvolvimento social, enquanto povo que atua e 
toma decisões com consciência; da ética e da moral enquanto população ativa nos processos decisórios que envolvem questões de ciência e tecnologia, e de estrutura econômica como Estado soberano.

Não há dúvidas que a atividade científica tenha trazido inúmeros benefícios para uma parte dos homens e mulheres do mundo. Por outro lado, a democratização e o acesso ao conhecimento científico e tecnológico e aos benefícios de suas conquisatas que, por um juízo moral e ético, deveriam atingir a maioria dos cidadãos do mundo, nunca se verificam na prática. Sabemos e vivenciamos de maneira bastante concreta as desigualdades que são produzidas a partir da negação do acesso a esse conhecimento básico.

A ciência figura como uma das mais importantes expressões culturais da humanidade, mas a sua importância não tem considerado valores éticos e princípios morais e sociais necessários para o estabelecimento de uma sociedade justa e verdadeiramente democrática. Nascida no contexto de uma sociedade capitalista, a ciência moderna beneficiou-se do sistema e contribui diretamente para a sua afirmação e consolidadação. O capitalismo de mercado apropriou-se do poder do conhecimento científico e, sem nenhum valor moral e ético, limita as conquistas da atividade científica ao monopólio do capital como propriedade privada de umas poucas dezenas de pessoas pertencentes as elites do mundo. Na procura pelo conhecimento verificado e certificado pelas comunidades de cientistas, a humanidade tem elaborado e refinado técnicas que lhe permitem atuar e intervir no mundo de forma cada vez mais eficaz.

A ciência, com a sua associação com a técnica, produziu algo novo no cenário mundial: a tecnologia. Esta é capaz de obter sucesso com muito mais rapidez, de produzir inovações que, há bem pouco tempo, eram consideradas sonhos de lunáticos e de trabalhar com os critérios da racionalidade sem precisar preocupar-se com a ética ou com as tradições. (BARROS, 2002, p. 28)

Dessa forma, a tecnologia como um dos principais produtos da atividade científica, instaura-se nos diversos setores da sociedade otimizando processos de produção e consumo, sendo utilizada cada vez mais por parte da humanidade e, essa, cada vez mais dependente dos produtos da ciência. Como exemplo, podemos citar o uso de aparelho eletrônicos como os computadores e celulares com as suas infinitas aplicações personalizáveis que tornam o cotidiano daqueles que conseguem traduzir as suas linguagens com tarefas diárias objetivas, diretas e automatizadas. Nem todo ser humano está apto a traduzir em termos práticos os benefícios dos aparatos tecnológicos, pois o acesso não se dá de forma igualitária e, em sua maioria, não estão interessados em como se dá o funcionamento dos objetos que por ele são utilizados. Interessa muito mais dominar a dinâmica necessária para a aquisição do artefato 


\section{POPUlARIZAÇÃo DA CIÊNCIA, SENSO COMUM E O PAPEL DO PROFESSOR}

tecnológico e possuindo-o, utilizá-lo de forma que possa lhe conferir status na comunidade em que participa, do que compreender os simples e complexos processos de funcionamento, embora não possa e até mesmo nem consiga utilizar todo o potencial que pode ser proporcionado. Seja na utilização de um computador, celular, carro, TV Smart, etc., não é difícil encontrar pessoas leigas nas funcionalidades e potencialidades dos objetos tecnológicos.

Nesse cenário, cabe então aos espaços formais e também não formais de educação, dentre eles a escola, o papel de prover os conhecimentos necessários para que a população seja alfabetizada cientifica e tecnologicamente, sendo capaz de apreender as explicações básicas que a ciência fornece para os diversos fenômenos que as tecnologias escondem e revelam, bem como a volatilidade apresentada pela natureza das coisas.

\footnotetext{
A explicação que a ciência oferece tem duas características fundamentais: por um lado, mantém um corpo coerente de conhecimento, de tal forma que a lógica e a razão estão sempre atuando e norteando o ato produtivo, embora nem sempre se manifeste no criativo. Por outro lado, ela oferece um quadro de explicações possíveis de um mundo natural que se mostra, cada dia com mais vigor, extremamente complexo. A ciência, entretanto, para evoluir, não pode se congelar, e as observações de novos fenômenos ou a explicação de fatos já conhecidos levam, necessariamente, a um caráter mutável: a ciência não pode manter uma unidade temporal. (BARROS, 2002, p. 35)
}

A não possibilidade da manutenção do caráter temporal da atividade científica exige não só dos espaços formais e não formais de educação, mas de toda a sociedade, uma postura permanentemente reflexiva e crítica perante o mundo, uma vez que os problemas a serem enfrentados e solucionados apresentam-se cada vez mais complexos, exigindo soluções individuais e coletivas ao mesmo tempo. Por outro lado, esta necessidade esbarra na precária formação de professores e professoras que não conseguem acompanhar as constantes transformações e atualizações do conhecimento científico impulsionado pela tecnologia que ele mesmo criou. As atividades na direção da socialização do conhecimento científico, a exemplo dos esforços de Popularização da Ciência e Tecnologia (PopC\&T), apresentam tantas limitações quanto possíbilidades. De modo que a utopia de uma nova ciência é tanto mais impossível quanto mais necessária.

A partir da ideia de Popularização da Ciência e Tecnologia sugerida por Germano(2008) e considerados os desafios impostos nas aproximações entre o conhecimento científico e os saberes do senso comum, nessa produção textual, sugerimos um ensino de ciências que considere as questões locais e regionais sugeridas por Candotti (2002). Conforme o autor é importante introduzir formas alternativas de apresentação da ciência de modo que se adeque 
a diferentes realidades.

É a partir da consideração da leitura e visão de mundo dos sujeitos pertencentes as comunidades, partindo da postura do professor-educador-intelectual comprometido e tendo a pedagogia da pergunta e o diálogo como princípio norteadores da prática educativa que o ensino de ciências pode contribuir para a gestação de uma ciência diferente. (FREIRE, 1996; FREIRE\&FAUNDEZ, 2011). Também através do autêntico diálogo elaborado a partir da diversidade nascida do encontro da ciência com o senso comum (GERMANO\&KULESZA, 2010, p. 123).

\section{Fundamentação teórica}

A aproximação do conhecimento científico, produto da atividade científica, com os saberes do senso comum, conhecimento prático advindo do cotidiano das pessoas em suas realidades, permitirá que as camadas marginalizadas da sociedade possam ter acesso a outra forma de compreensão da realidade, com uma aproximação cada vez mais crítica do objeto cognocível. Por outro lado, o diálogo da ciência com as demandas populares, reconfigura a reflexão crítica dos cientistas e intelectuais que, problematizados pelas classes populares começam a orientar a sua criatividade para outras questões e outros modelos de sociedade.

Assim como as práticas são diferenciadas, o conceito de popularização da ciência também é diversificado, apresentando variações que em alguns casos se confunde com divulgação científica, vulgarização da ciência, letramento ou alfabetização científica. Neste artigo, estamos sugerindo que a conceituação apresentada por Germano (2008) se adequa melhor aos objetivos de uma reflexão teórica-prática orientadas para o estabelecimento de práticas educativas populares.

[...] popularizar é muito mais do que vulgarizar ou divulgar a ciência. É coloca-la no campo da participação popular e sob o crivo do diálogo com os movimentos sociais. É convertê-la ao serviço e às causas das maiorias e minorias numa ação cultural que, referenciada na dimensão reflexiva da comunicação e no diálogo entre diferentes, oriente suas ações respeitando a vida cotidiana e o universo simbólico do outro. (GERMANO, 2008, p. 305)

A conceituação exposta acima põe o diálogo e a comunicação horizontal como as condições necessárias para o início de um processo de popularização da ciência; mais do que isso, será a partir do diálogo e da comunicação horizontal entre os diferentes que inaugurar-seá uma aproximação entre o conhecimento científico e os saberes do senso comum e o mútuo 
POPULARIZAÇÃO DA CIÊNCIA, SENSO COMUM E O PAPEL DO PROFESSOR

enriquecimento de ambos: um senso comum mais esclarecido e uma ciência mais decente e mais prudente.

Nesse sentido, o papel que o educador desenvolverá nos espaços formativos será o de indivíduo que aprende com o processo de ensino e aprendizagem e na busca constante pela apreensão dos saberes dos sujeitos envolvidos na dinâmica dialógica do percurso gnosiológico. Estas são características da prática educativa que se colocam como exigências que devem ser assumidas pelo professor no seu papel de apresentar a ciência ao povo.

Refiro-me à insistência com que, desde longo tempo, defendo a necessidade que temos, educadoras e educadores progressistas, de jamais subestimar ou negar os saberes de experiência feitos, com que os educandos chegam à escola ou aos centros de educação informal. [...] Em qualquer deles, porém, subestimar a sabedoria que resulta necessariamente da experiência sociocultural é, ao mesmo tempo, um erro científico e a expressão inequívoca da presença de uma ideologia elitista. (FREIRE, 2019, p. 117)

Educandos e educandas vindos das mais diversas realidades de vida trazem consigo um conjunto de experiências feitas que ao longo de suas vidas foram construídas de modo individual e coletivo. Representam de forma fiel a leitura e visão que detêm do mundo e dada a importância desse saber, a sua consideração e apreensão por parte do educador comprometido significa a possibilidade de transformação da realidade numa junção dialógica e democrática entre teoria e prática. Dessa forma, a ideia de Popularização da Ciência apontada e defendida nesse texto, vai de encontro aos direitos defendidos por Freire (2019) quando da sua

[...] ênfase na ligação educação-consciência sob o ponto de vista gnosiológico. O direito ao (1) conhecimento "do que antes se conhecia de outra forma" e ao (2) conhecimento "do que não se conhecia", oportunizando (3) a produção/criação de um "conhecimento próprio" por parte dos subalternos, mostra a preocupação de ler o pedagógico em sua plenitude política. (SCOCUGLIA, 2015, p. 68)

Dentre as inúmeras justificativas que são apresentadas para a promoção da PopC\&T (GERMANO, 2008, p. 306-336) apresenta algumas das mais citadas. Dessa forma: uma melhor apreciação estética da realidade apresenta-se como forma de obtenção de um conhecimento científico e tecnológico permitindo ao sujeito a apreciação de fenômenos e objetos tecnológicos de maneira mais pormenorizada; para melhorar o financiamento público da ciência: uma maior compreensão da população acerca da atividade científica teria como consequência o aumento do apoio ao financiamento da ciência; para impulsionar o desenvolvimento econômico: a atração dos jovens brasileiros talentosos para carreira científica aumentaria os pesquisadores e 
os produtos tecnológicos contribuiriam com a economia do pais; para o controle social da ciência: uma população alfabetizada científica e tecnológicamente, participaria de modo mais efetivo nos processos decisórios que envolvem questões relacionadas a projetos científicos; para combater pseudociências: próxima ao povo a ciência atuaria como critério de avaliação de ideologias propagadas nos meios populares, auxiliando no combate as pseudociências; para desmistificar a própria ciência: desmistificaria a visão da ciência e do cientista como atividade de gênios, bem como deixará transparecer os limites da atividade científica e promoveria uma maior inclusão social.

Decerto que a intromissão do povo em questões polêmicas envolvendo ciência e tecnologia, apesar de reconhecidamente necessária, reclamaria um conhecimento mais do que elementar e uma forma de organização da sociedade que garantisse mecanismos de participação e controle, o que ainda está muito aquém de nossas reais possibilidades. (ibidem, 2008, p. 341)

Ao levarmos em consideração a realidade educacional brasileira, verificamos que de fato estamos numa situação que não nos traz muitas esperanças. Parte reside no desinteresse da maior parte da população por aspectos ligados a ciência e tecnologia, por ser um assunto de "gênios", e a outra residindo na inexperiência democrática do nosso povo. Referindo-se a esta questão, o educador Paulo Freire nos diz no livro Pedagogia da Esperança (2019):

O que me parece fundamental para nós, hoje, mecânicos ou físicos, pedagogos
ou pedreiros, marceneiros ou biólogos é a assunção de uma posição crítica,
vigilante, indagadora, em face da tecnologia. Nem, de um lado,
demonologizá-la, nem, de outro, divinizá-la. Nunca, talvez, a frase quase feita
- exercer o controle sobre a tecnologia e pô-la a serviço dos seres humanos -
teve tanta urgência de virar fato quanto hoje, em defesa da liberdade mesma,
sem a qual o sonho da democracia se esvai. (FREIRE, 2019, p. 184)

As implicações e desafios envolvidos nos esforços da PopC\&T nas aproximações entre saber científico e os saberes do senso comum, referimo-nos agora as limitações e possibilidades frente as justificaticas apresentadas. Para a potencialidade estética, onde se coloca a problemática da insensibilidade e do desencantamento da natureza, e do mundo quando das explicações fornecidas pela ciência e a sua, já citada, volatilidade. De modo que "[...] considerando o que a ciência produz um desencatamento do mundo e ao explicar a realidade a partir de categorias universais, subtrai muito de seu deslumbramento mais próximo de um olhar inocente e de senso comum." (GERMANO, 2008. p. 347) Quando voltada para o desenvolvimento econômico, ensejaria uma política que estabelecesse objetivos claros para 
POPULARIZAÇÃo DA CIÊNCIA, SENSO COMUM E O PAPEL DO PROFESSOR

assegurar e gerar fontes de renda, aumentar o interesse de jovens talentos para a atividade científica, bem como num planejamento de nação que tenha como base o seu desenvolvimento econômico alicerçado no desenvolvimento da ciência e tecnologia. É, nesse sentido, que

[...] a popularização do conhecimento científico e tecnológico estaria orientada para atrair novo interesse da sociedade pela ciência, despertando novas vocações científicas, maior contingente de pesquisadores, maior quantidade de pesquisas e aplicações tecnológicas com geração de divisas para o país e novas remessas de verbas destinadas à ciência e tecnologia."(ibidem, 2008, p. 347)

Para a obtenção de financiamentos dos projetos científicos, chama-se atenção para o fato da mercantilização da atividade científica, através da submissão das descobertas do conhecimento científico aos interesses do mercado financeiro e do lucro inescrupuloso. Dessa forma, a ciência a ser apresentada para os patrocinadores, seja ele estatal ou privado, objetivando o seu financiamento estará direcionada para os interesses do povo ou a especulações de caráter privado? "Não é qualquer ciência que pode pretender-se popular, como não vai ser qualquer projeto científico que vai querer abrir mão do controle de seus segredos e da proteção de suas patentes, libertando a criatividade do jugo imperativo do mercado."(ibidem, 2008, p. 349) Quanto ao papel que os esforços PopC\&T podem assumir na desconstrução da ciência como atividade de "gênios", indivíduos "privilegiadas pela natureza", homens e mulheres de jaleco branco trancafiados em prédios sem expressão alguma, se reflete na maneira de como se comunicam ao fazerem uso de uma linguagem que poucas pessoas conseguem entender. Impera a ideia de que o povo é totalmente leigo e avesso ao conhecimento científico, e, por esse mesmo motivo, qualquer esforço na direção de ajudar a compreender as linguagens da ciência é um tempo perdido. Logo “[...], quando se fala em PopC\&T parte-se de um princípio que absolutiza a ignorância, dispondo, de um lado, o público popular, considerado leigo e ignorante, e do outro, os cientistas, que são os protagonistas do conhecimento.” (ibidem, 2008. p. 352) Essa visão da ciência, praticada por deuses e deusas, ganha terreno nas iniciativas distorcidas de divulgação da história da ciência com seus relatos incompletos, parciais e, principalmente, míticos dos personagens das descobertas científicas, como também no elitismo intelectual encontrado entre os cientistas.

Criticar a arrogância, o autoritarismo de intelectuais de esquerda ou de direita, no fundo, da mesma forma reacionários, que se julgam proprietários, os primeiros, do saber revolucionário, os segundos, do saber conservador, criticar o comportamento de universitários que pretendem conscientizar trabalhadores 
rurais e urbanos sem com eles se conscientizar também, criticar um indisfarçável ar de messianismo, no fundo ingênuo, de intelectuais que, em nome da libertação das classes trabalhadoras, impõem ou buscam impor a "superioridade" de seu saber acadêmico às "incultas massas", isto sempre fiz. E disto falei quase exaustivamente na Pedagogia do Oprimido. E disto falo agora, com a mesma força, na Pedagogia da Esperança. (FREIRE, 2019, p. 110)

Assim, a aproximação do conhecimento científico com a população e seus saberes se colocam pela promoção, conquista e fundamentação de uma sociedade mais inclusiva e que possibilita o acesso a direitos básicos e, também, na luta pelo direito de permanecer com eles. A desmistificação social da ciência e de seus praticantes contribuirá para o estabelecimento do diálogo com as diversas realidades que se apresentam e influenciam os processos de ensino e aprendizagem e, assim, possam de fato atender as necessidades de aprendizagem dos sujeitos pertencentes às camadas populares. Por fim, como consequência direta dos trabalhos empreendidos da PopC\&T na desmistificação da ciência, também se justifica no combate contra as pseudociências tão presentes nos meios populares. Os sujeitos pertencentes a essas camadas da sociedade vivem suas cotidianeidades amparados por seus saberes constituídos ao longo de suas histórias de vida e resultado das diversas experiências na luta pela sobrevivência. Porém, esse conhecimento não é suficiente para desvendar charlatanices, explicações míticas dos fenômenos e problemas da vida, falsas religiosidades bem como produtos enganosos ou serviços fraudulentos. A necessidade de se criar as condições pertinentes para o estabelecimento de um diálogo entre a realidade de vida do indivíduo com o conhecimento científico e sua consecutiva apreensão desses saberes, possibilita a criação e o estabelecimento de práticas e posturas que os defendam de falsas promessas.

Menos arrogante e com algum otimismo, é possível que, apoiados em requisitos existenciais de uma comunicação dialógica, seja possível trabalhar com o povo questões de ciência, sem necessariamente ficar contra ele, estabelecendo um diálogo em torno de questões simples de seu quotidiano, até avançar para uma compreensão metódica e mais elaborada da realidade."(GERMANO, 2008, p. 360)

De todo modo, o educador imerso deve se preocupar em apresentar a ciência e as suas práticas tão próximas da realidade de vivência do indivíduo que deseje ou esteja em um processo de alfabetização científica-tecnológica. Problematizar a realidade para estabelecer uma significância permanente do cotidiano do educando considerando seu modo ver, perceber, julgar e agir como próprios da sua relação com o meio que vive e, assim, oportunizar processos 
POPULARIZAÇÃo DA CIÊNCIA, SENSO COMUM E O PAPEL DO PROFESSOR

criativos e concretos de intervenção.

\section{Metodologia}

O referido texto busca através de uma revisão bibliográfica dos escritos do educador popular Paulo Freire (FREIRE, 2019, 2011, 1996), e dos esforços empreendidos comumente denominados de Popularização da Ciência e Tecnologia (PopC\&T) em (GERMANO, 2008), refletir sobre a importância da consideração dos saberes dos integrantes das camadas populares na promoção de um processo de ensino e aprendizagem que possibilite a aproximação do conhecimento científico com suas leituras e visões de mundo.

A partir da leitura dos textos de Freire refletimos sobre a necessidade do professor se colocar como um educador compromissado em apreender os saberes de experiências dos sujeitos das comunidades populares através do estabelecimento do diálogo nas aulas do ensino de ciências. Tal atitude, lhe permitirá apresentar o conhecimento científico como um produto, porém como uma atividade que pode se adequar ao contexto de vivência do educando.

Para tanto, apresenta-se a partir das reflexões de Germano (2008) as justificativas para a promoção da Popularização da Ciência e Tecnologia (PopC\&T) nos espaços educativos, bem como os desafios e as limitações que são impostas a cada uma delas.

Dessa forma, a pedagogia da pergunta defendida por Freire é adotada como princípio pedagógico como forma de instaurar processos de ensino e aprendizagem dialógicos no ensino de ciências em contraponto ao ensino bancário, exímio em depositar conteúdos que muitas vezes não fazem parte da realidade cotidiana dos sujeitos das camadas populares.

\section{Resultados e Discussões}

Numa postura de humildade e encantamento pelo cotidiano é que os professores poderão apreender a realidade dos sujeitos das camadas populares e as suas curiosidades adquirindo o conhecimento necessário para melhor abordarem as situações-problemas e elaborarem coletivamente soluções adequadas ao local e ao regional. A consideração da fala, do desejo, do anseio, do grito, da expressão corporal, dos seus gostos e costumes torna-se uma condição fundamental para a exploração da PopC\&T através dos esforços emprendidos.

O trabalho educativo do professor compromissado com sua postura enquanto educador reflexivo-crítico deve, então, sujeitar-se a leitura e visão de mundo dos sujeitos do processo educativo enquanto condição fundamental para o estabelecimento de um ensino de ciências 
dialógico. É nesse sentido, que Paulo Freire aponta duas qualidades imprescindíveis para o trabalho com o povo: a imaginação criadora do intelectual com o qual se sujeitará a massa “[...]à marcante capacidade imaginativa das massas, com o que se ajudará a desenvolver a sua[...]" (FREIRE; FAUNDEZ, 2011, p. 106) e a sensibilidade histórica que é “[...]essa capacidade de prever, de antever, quase de adivinhar, que aprendemos com a prática também, se estamos aberto a este aprendizado.” (FREIRE; FAUNDEZ, 2011, p. 107) O intelectual comprometido fará de sua prática educativa um trabalho "com" os integrantes da realidade, e não "para" ou "sobre" eles e elas, mas, insistentemente, "junto com" as suas subjetividades, leitura e visão de mundo, sonhos e desejos.

Pensar certo, do ponto de vista do professor, tanto implica o respeito ao senso comum no processo de sua necessária superação quanto o respeito e o estímulo à capacidade criadora do educando. Implica o compromisso da educadora com a consciência crítica do educando cuja "promoção" da ingenuidade não se faz automaticamente. (FREIRE, 1996. p. 29)

O educador intelectual que utilizará o conhecimento científico como elemento mediador com os saberes do senso comum, submetendo-se aos complexos processos de pensamento do povo conseguirá estabelecer um processo de ensino e aprendizagem capaz de apreender as especificidades e singularidades da situação comunicativa entre o conhecimento científico e o senso comum.

Os sujeitos ao se verem e perceberem como elemento integrador da investigação, da intervenção e transformação da realidade se sentirão importantes, pois suas falas, retrato fiel de suas necessidades são consideradas contribuições para a elaboração da solução de um problema. É justamente isso que significa trabalhar "com" o povo e não "para" eles ou "sobre" eles: o educador ter a consciência de que sem as considerações de seus saberes de experiências feitos, não se conseguirá chegar a lugar algum.

Cabe a nós, educadores, e não aos alunos, a responsabilidade e o trabalho de adaptar o que queremos ensinar às condições locais em que vivem e se movem os nossos alunos. Adequá-lo ao seu modo de imaginar e representar e também aos exemplos e histórias que encontramos no cotidiano do lugar onde vivemos. E isso, mesmo naqueles casos em que é nossa intenção propiciar a mudança dessas formas de representação e explicação. (CANDOTTI, 2012, p. 23)

A união da teoria e da prática coloca-se, dessa forma, como uma das condições fundamentais para os desafios impostos pela realidade aos trabalhos realizados na direção 


\title{
POPULARIZAÇÃO DA CIÊNCIA, SENSO COMUM E O PAPEL DO PROFESSOR
}

PopC\&T. Trata-se de refletir a prática educativa nos espaços formais e não-formais e, ao mesmo tempo, para não incorrer em achismos, pôr-se em ação objetivando a transformação da realidade. Estimular o contato entre os diferentes, a troca de experiências, a escuta do outro e, fazendo-se necessário, a instauração do silêncio. Não do silêncio submetido pelo autoritarismo, pela negação do outro como ser, pela imposição dogmática do que se deve aprender e o que será ou não será considerado na investigação do objeto de estudo. Trata-se do silêncio que fala, que inquieta, que perturba e, acima de tudo, que manifesta a espera e a paciência da sabedoria que o povo possui.

\begin{abstract}
Assim, quando sugerimos a possibilidade de diálogo entre os saberes populares e o conhecimento científico, não estamos apenas elucubrando um sonho impensável e impossível. Pelo contrário, trilhamos os caminhos de uma nova ciência que começa a vincular conhecimento local e conhecimento global e reconhecer a afetação intransponível entre observador e observável, em um conhecimento que se encanta e se encontra no que encontra; que se emociona e se vê no que vê. Em face disso, torna-se inevitável reconhecer que o diálogo entre o conhecimento científico e os saberes de senso comum tanto é possível, como viável e imprescindível. Não obstante, os esforços para uma efetiva PopC\&T demandam, além de uma nova postura diante do senso comum, a gênese de uma nova ciência muito mais envolvida e comprometida com os interesses populares. (GERMANO, 2008, p. 354-355).
\end{abstract}

Os frutos de uma população que seja capaz de atuar cientificamente frente aos desafios impostos pela sociedade só se tornarão concretos passando pela aceitação de que não só a ciência é capaz de solucionar os problemas, mas também o senso comum que "[...]é exímio em captar a profundidade horizontal das coisas, fornecendo generalizações imediatas e fundamentais para o movimento e a sobrevivência da espécie.” (GERMANO\&KULESZA, 2010, p. 123). Por outro lado, para o enfrentamento de uma sociedade desigual, injusta e inescrupulosa que constrói seus valores a partir de critérios excludentes objetivando a manutenção de privilégios e criando cada vez mais processos de exclusão, faz-se necessário refletir e pôr em prática novas abordagens, pontos de contatos e metodologias com o conhecimento científico. Isto é, superar a ideia de que a ciência e todos os seus artefatos não podem ser acessíveis ao povo e de que, o senso comum, o saber de experiência, não possui valor algum.

Esse intelectual menospreza o saber que não é científico e, inconscientemente, saber popular; para o intelectual e político, o senso comum popular mostra-se como um não saber e, enquanto não saber, como um não poder [...] Creio que uma das coisas que o intelectual deve aceitar é que esse saber popular é de uma riqueza sociológica fundamental para qualquer ato político, para qualquer 
ato de transformação da sociedade. [...] O saber "científico" transforma-se em científico apenas à medida que ele se apropria do saber popular. E o saber popular se transforma num saber de ação e transformação eficaz quando se apropria, por sua vez, de forma criativa, deste saber "científico" proposto pelo intelectual. (FREIRE; FAUNDEZ, 2011, p. 84)

Como então, o educador poderá propiciar dentro e fora da sala de aula a aproximação entre os saberes científicos? De que forma poderá apreender as concepções que os sujeitos participantes do processo de ensino e aprendizagem possuem acerca do mundo e de suas realidades? Que postura deverá assumir para poder operar os conhecimentos científicos com os saberes do senso comum e instaurar um processo coletivo de aprendizagens mútuas?

Sem dúvida nenhuma, será a partir de uma postura humilde e desnudada de vaidades e raciocínios prontos. Vazio de preconceitos e juízos de valor acerca dos sujeitos e de suas condições sócio-econômicas-histórico-culturais. Será no estímulo a curiosidade, a pergunta e na consideração da ingenuidade do educando, pois elas tem muito a revelar. $\mathrm{Na}$ apropriação da pedagogia pergunta como princípio pedagógico e não na resposta, na valorização da dinâmica do processo de ensinar e de aprender, desapegando-se do produto final como único objeto a ser avaliado e validado.

Insisto em que a educação em geral é uma educação de respostas, em lugar de ser uma educação de perguntas. Uma educação de perguntas é a única educação criativa e apta a estimular a capacidade humana de assombrar-se, de responder ao seu assombro e resolver seus verdadeiros problemas essenciais. E o próprio conhecimento. (FREIRE; FAUNDEZ, 2011, p. 75-76)

Na promoção do processo de ensinar e aprender com características democráticas, o educador progressista coloca-se como um contínuo aprendiz da vida, dos sujeitos e de suas realidades respondendo as suas perguntas na consideração das perguntas dos Outros. A troca de experiências e saberes, e a interação promovida entre as curiosidades que educador e educando possui, diminui-se a distância entre o conhecimento científico e os saberes do senso comum, tornando-os em um conhecimento prudente e esclarecido.

\section{Conclusões}

A instauração de um ensino de Ciências que tenha como objetivo alfabetizar cientificamente e tecnologicamente indivíduos suficientemente capazes de atuarem na sociedade de modo prudente, crítico, articulado, inclusivo, propositivo e democrático deve ser 
POPULARIZAÇÃo DA CIÊNCIA, SENSO COMUM E O PAPEL DO PROFESSOR

um projeto assumido não só por cientistas e profissionais da educação e demais áreas, mas, ser antes de tudo, uma política de Estado que elabora, patrocina e apoia ações dessa natureza.

O projeto de desenvolvimento de uma nação soberana passa pela valorização dos talentos de seu povo e pela descentralização das ações de fomento a uma educação científica de qualidade e adequada as regionalidades de cada local. Dessa forma, a apresentação da ciência de uma forma diferenciada por parte do educador reflexivo-crítico além de propiciar o desenvolvimento científico, tecnológico, econômico e social do país permitirá que a população, inserida e comprometida com as suas realidades possam fazer o mesmo.

As iniciativas da Popularização da Ciência e Tecnologia (PopC\&T) por meio de uma comunicação horizontal reflexiva entre os diferentes numa perspectiva igualitária, coloca-se como uma alternativa que apresenta a ciência como uma atividade humana, dialogue com o local e o regional considerando suas especificidades e singularidades. Os desafios que se colocam frente a uma ciência que se objetive popular são muitos passando por uma pretensa necessidade de possuir um mínimo de conhecimento científico e tecnológico para viver bem, não se tornar vítima de charlatanices, possuir certo grau de poder, pois conhecimento é poder, indo até uma consciência cívica que faça o sujeito se inserir nos processos decisórios de políticas públicas que envolvem sua comunidade e o seu país.

Dessa forma, para que a ciência se torne acessível a maioria da população, urge refletir sobre a instauração de processos educacionais dialógicos que considerem a leitura e a visão de mundo dos educandos. Educadores como aprendizes que sejam capazes de apreender as características e as necessidades de aprendizagens da comunidade, através da investigação coletiva e a elaboração democrática de soluções adequadas para os problemas.

Uma educação de perguntas, da reflexão e da ação, em contraponto a hegemônica educação das respostas pronta para depositar "saberes" nos homens e nas mulheres. Uma educação que criticiza o ato de aprender e se reflete na prática como fruto dos diálogos entre a teoria e a prática, porque não tem vergonha e nem medo do que pode encontrar. Uma educação que considera e até o estimula o conflito, pois se trata de uma condição natural de homens e mulheres imersos no mundo para trilharem suas vocações: a de serem mais!

\section{Referências}

BARROS, Henrique. A Cidade e a Ciência. In. MASSARANI, L; MOREIRA, Ildeu de C. \& BRITO, F. (orgs.) Ciência e Público: caminhos da divulgação científica no Brasil. Rio de Janeiro, Casa da Ciência. UFRJ, 2002. 
CANDOTTI, Ennio. Ciência na Educação Popular. In. MASSARANI, L; MOREIRA, Ildeu de C. \& BRITO, F. (orgs.) Ciência e Público: caminhos da divulgação científica no Brasil. Rio de Janeiro, Casa da Ciência. UFRJ, 2002.

FREIRE, Paulo. Pedagogia da Esperança: um reencontro com a pedagogia do oprimido. $26^{\circ}$ ed. São Paulo/Rio de Janeiro: Paz e Terra, 2019.

FREIRE, Paulo. Pedagogia do Oprimido. Rio de Janeiro/ São Paulo: Paz e Terra, 2019.

FREIRE, Paulo. Pedagogia da Autonomia: Saberes necessários à prática educativa. $4^{\circ}$ ed. São Paulo: Paz e Terra, 1996 (Coleção Leitura)

FREIRE, Paulo; FAUNDEZ, Antonio. Por uma pedagogia da pergunta. $7^{\circ}$ ed. São Paulo: Paz e Terra, 2011.

GERMANO, Marcelo Gomes. Uma nova ciência para um novo senso comum [online]. Campina Grande: EDUEPB, 2011. 400 p. ISBN 978-85-7879-072-1. Available from SciELO Books <http://books.scielo.org>.

GERMANO, Marcelo Gomes.; KULESZA, Wojciech. Ciência e Senso Comum: entre rupturas e continuidades. Caderno Brasileiro de Ensino de Física. v. 27, n. 1: p. 115-135, abr. 2010.

SCOCUGLIA, Afonso Celso. História das ideias de Paulo Freire e a atual crise dos paradigmas. $6^{\circ}$ ed.- João Pessoa: Editora da UFPB, 2015. 192 p. 